\title{
Predicted clinical factors associated with the intensive care unit length of stay after total cavopulmonary connection
}

\author{
Masamichi Ono, MD, PhD, ${ }^{\mathrm{a}, \mathrm{b}}$ Melchior Burri, MD, ${ }^{\mathrm{a}, \mathrm{b}}$ Gunter Balling, MD, ${ }^{\mathrm{c}}$ Elisabeth Beran, MD, \\ Julie Cleuziou, MD, ${ }^{\mathrm{a}, \mathrm{b}}$ Jelena Pabst von Ohain, MD, PhD, ${ }^{\mathrm{a}, \mathrm{b}}$ Martina Strbad, MS, ${ }^{\mathrm{a}, \mathrm{b}}$ \\ Alfred Hager, $\mathrm{MD}, \mathrm{PhD},{ }^{\mathrm{c}}$ Jürgen Hörer, $\mathrm{MD}, \mathrm{PhD},{ }^{\mathrm{d}}$ and Rüdiger Lange, $\mathrm{MD}, \mathrm{PhD}^{\mathrm{a}, \mathrm{b}, \mathrm{e}}$
}

\section{ABSTRACT}

Objectives: A longer length of stay (LOS) in the intensive care unit (ICU) after the total cavopulmonary connection (TCPC) is thought to be a predictive sign of late Fontan failure. This study was performed to determine the clinical risk factors for ICU LOS.

Methods: In total, 483 patients who underwent a TCPC between May 1994 and December 2016 were included the study. Patients' main diagnosis, morphologic characteristics, palliative procedures, hemodynamic parameters, and perioperative variables, were analyzed to identify risk factors influencing ICU stay based on Cox regression. Causes of longer ICU LOS and the impact of ICU LOS on late outcomes were evaluated.

Results: Age at TCPC, type of TCPC, and fenestration at TCPC did not affect the ICU LOS. With multivariable model, hypoplastic left heart syndrome $(P=.001)$ and anomalous systemic venous drainage $(P<.001)$ were identified as independent morphologic risk factors for prolonged ICU LOS. Of hemodynamic variables, preoperative high transpulmonary gradient $(P=.037)$, and low aortic oxygen saturation $(P=.031)$ were risks for longer ICU LOS. Of postoperative variables, pleural effusion $(P<.001)$, chylothorax $(P=.001)$, ascites $(P<.001)$, and infection $(P=.028)$ were risks for longer ICU LOS. The ICU LOS was found to be significantly associated with late mortality $(P<.001)$ and late cardiac reoperation $(P=.007)$.

Conclusions: Patients with hypoplastic left heart syndrome and anomalous systemic venous drainage had longer ICU LOS. Extended cyanosis and elevated pulmonary artery pressure affect the ICU LOS. Special care should be provided during the initial postoperative phase in patients with such risk factors. (J Thorac Cardiovasc Surg 2019;157:2005-13)

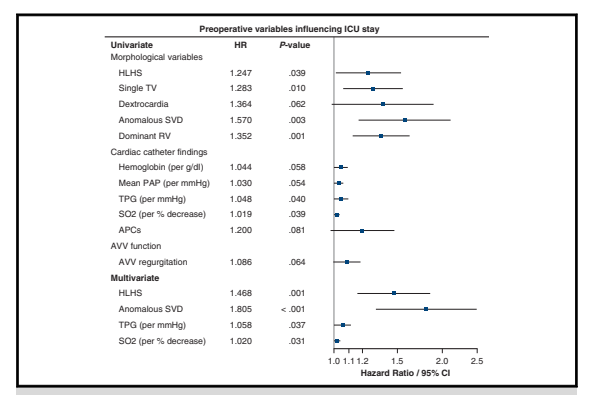

Preoperative risk factors for longer ICU stay after TCPC.

\section{Central Message}

HLHS and anomalous SVD were morphologic risks for longer ICU stay. Extended cyanosis, elevated pulmonary artery pressure, and presence of aortopulmonary collaterals affected the length of ICU stay.

\section{Perspective}

Certain morphologic and hemodynamic features were associated with longer ICU LOS after TCPC. Similar to previous reports, prolonged longer ICU LOS stay is a significant risk factor for late outcomes. Special attention is needed for postoperative care in patients with HLHS and anomalous SVD. The presence of APCs might cause postoperative complications.

See Commentaries on pages 2014 and 2016.

\footnotetext{
From the ${ }^{\mathrm{a}}$ Department of Cardiovascular Surgery, ${ }^{\mathrm{c}}$ Department of Pediatric Cardiology and Congenital Heart Disease, and ${ }^{\mathrm{b} I n s u r e ~(I n s t i t u t e ~ f o r ~ T r a n s l a t i o n a l ~ C a r d i a c ~}$ Surgery), Department of Cardiovascular Surgery, German Heart Center Munich, Technische Universität München, Munich, Germany; ${ }^{\mathrm{d}}$ Department of Congenital Heart Disease, Marie Lannelongue Hospital, Les Plessis-Robinson, France; and ${ }^{\mathrm{e}}$ German Center for Cardiovascular Research, Munich, Germany.

This study was supported by grants from the Werner Reichenberger Foundation for Child Health.

Received for publication March 26, 2018; revisions received Oct 23, 2018; accepted for publication Oct 24, 2018; available ahead of print Dec 18, 2018.

Address for reprints: Masamichi Ono, MD, PhD, Department of Cardiovascular Surgery, German Heart Center Munich at the Technical University, Lazarett Straße 36, 80636 Munich, Germany (E-mail: ono@dhm.mhn.de).

$0022-5223 / \$ 36.00$

Copyright (C) 2018 by The American Association for Thoracic Surgery

https://doi.org/10.1016/j.jtcvs.2018.10.144
}

Recently, Downing and colleagues ${ }^{1}$ demonstrated in their large single-center study that long post-Fontan intensive care unit (ICU) stay is a strong risk factor for worse early and late outcomes. Our previous study also showed that longer length of stay (LOS) in the ICU after total

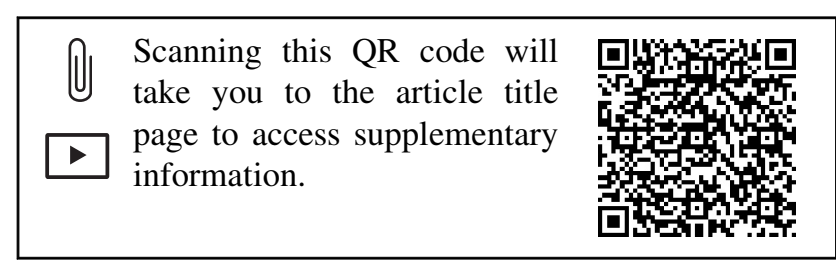




\author{
Abbreviations and Acronyms \\ APCs $=$ aortopulmonary collaterals \\ $\mathrm{AVV}=$ atrioventricular valve \\ BCPS = bidirectional cavopulmonary shunt \\ $\mathrm{CPB}=$ cardiopulmonary bypass \\ HLHS $=$ hypoplastic left heart syndrome \\ ICU = intensive care unit \\ LOS = length of stay \\ PA = pulmonary artery \\ PAP = pulmonary artery pressure \\ $\mathrm{RV}=$ right ventricle \\ $\mathrm{SO}_{2}=$ aortic oxygen saturation \\ SVD $=$ systemic venous drainage \\ $\mathrm{TCPC}=$ total cavopulmonary connection \\ $\mathrm{TPG}=$ transpulmonary gradient
}

cavopulmonary connection (TCPC) was associated with late mortality, reoperation, and catheter intervention. ${ }^{2}$ In clinical practice, we cannot accurately predict longer ICU LOS after TCPC. We observed that certain patients needed longer ICU LOS, both with and without high preoperative risk. Postoperative ICU stay can be prolonged by pleural effusion, chylothorax, ascites, arrhythmia, and infections. Previous studies demonstrated that postoperative ICU LOS was influenced by the following factors: systemic right ventricle (RV), ${ }^{3}$ hypoplastic left heart syndrome (HLHS), ${ }^{4}$ longer hospital stay at stage II and pre-Fontan complications, ${ }^{5}$ lower preoperative aortic oxygen saturation $\left(\mathrm{SO}_{2}\right){ }^{6}$ high volume expansion, ${ }^{7}$ and viral season (November to March), ${ }^{8}$ as well as fenestration at TCPC. ${ }^{9}$

In the present study, we analyzed our large cohort of functional single-ventricle patients who underwent TCPC and intended to identify the risk factors predicting longer ICU LOS. We also evaluated the causes of longer ICU LOS and the impact of ICU LOS on late outcomes.

\section{PATIENTS AND METHODS \\ Patients' Inclusion Criteria}

This single-center retrospective cohort study considered all patients who underwent a TCPC at the German Heart Center Munich between May 1994 and December 2016 for inclusion. TCPC included the intracardiac lateral tunnel and extracardiac conduit techniques. Patients who underwent Fontan conversion from "classic" atriopulmonary Fontan to extracardiac TCPC were excluded from this study. Patients were identified using our institutional database. Demographic, morphologic, clinical, operative, and hospital information were abstracted from the medical records. Approval of this study was obtained from the institutional review board of the Technical University Munich; the need for individual patient consent was waived for this retrospective, observational study.

\section{Surgical Techniques and Postoperative Management}

The surgical techniques for a TCPC were described in our previous report. ${ }^{10}$ Fenestration was not routinely performed and was only used for high-risk patients. Indications for fenestration ${ }^{11}$ and for atrioventricular valve (AVV) surgery ${ }^{12}$ were described in our previous report. Stage II palliation was a bidirectional cavopulmonary shunt (BCPS), and antegrade pulmonary blood flow was terminated at this procedure. ${ }^{13}$ Since 2009 , we adopted an early extubation strategy after TCPC. ${ }^{14}$

\section{Follow-up}

Postdischarge outcomes were determined from outpatient clinic documentation in the electronic patient chart of the German Heart Center Munich or from direct correspondence with referring pediatric cardiologists. Mortality was ascertained at each of the follow-up sites through direct contact with the families and attending physicians.

\section{Identification of Factors Affecting Prolonged ICU Stay}

To identify risk factors for longer ICU LOS, we evaluated the variables related to the patients' primary diagnosis, cardiac morphology, palliative surgeries, and other preoperative conditions (Table E1).

\section{Statistical Analysis}

Continuous variables are expressed as means \pm standard deviations or medians with interquartile ranges, if appropriate. Kaplan-Meier curves were constructed to estimate probability of ICU discharges, overall survival, freedom from reoperation, and from catheter intervention. Time zero was defined as the date of TCPC, and failure was defined as heart transplantation or death within the study period. Patients alive without transplant were censored at the end of the study period. Risk factor analysis of preoperative and operative variables was performed using uni- and multivariable Coxregression analysis. Risk factor analysis of postoperative variables was performed using Cox model with time varying covariates. Those variables with a $P<.1$ in univariable analysis were considered for entry into the multivariable models. $P<.05$ was considered significant. Analysis was conducted with Statistical Package for the Social Sciences (SPSS), version 22.0 for Windows (IBM Corp, Ehningen, Germany).

\section{RESULTS \\ Preoperative Variables}

A total of 483 patients underwent TCPC at the German Heart Center Munich during the study period. Baseline characteristics of the study cohort are displayed in Table 1. In brief, the median age at TCPC was 2.3 years, and the most frequent primary diagnosis was HLHS $(\mathrm{n}=120,24.8 \%)$. Dominant RV was observed in 261 (54\%), and anomalous systemic venous drainage (SVD) was observed in $53(11.0 \%)$ patients. Patients with anomalous SVD had significant high association with dominant $\mathrm{RV}(81.1 \%, P<.001)$, heterotaxy $(47.2 \%, P<.001)$, common atrioventricular valve $(43.4 \%, P<.001)$, dextrocardia $(32.1 \%, P<.001)$, and anomalous pulmonary venous drainage $(28.3 \%, P<.001)$, as compared with patients with normal SVD. Staged Fontan completion after BCPS was performed in $434(89.9 \%)$ patients. Preoperative cardiac catheterization and echocardiographic data are shown in Table E2. The mean pulmonary artery pressure (PAP) was $9.6 \mathrm{~mm} \mathrm{Hg}$ and the mean transpulmonary gradient (TPG) was $3.9 \mathrm{~mm} \mathrm{Hg}$. Significant aortopulmonary collaterals (APCs) were present in $126(26.7 \%)$ patients. Impaired ventricular function was observed in $44(9.1 \%)$ patients, and moderate AVV regurgitation was observed in $56(11.6 \%)$ patients and severe in $7(1.4 \%)$. 
TABLE 1. Baseline characteristics of patients

\begin{tabular}{|c|c|}
\hline Variables & n $(\%)$ or median (IQR) \\
\hline Number of patients & 483 \\
\hline Age at TCPC, y & $2.3(1.8-3.8)$ \\
\hline Weight at TCPC, $\mathrm{kg}$ & $12.0(10.6-14.5)$ \\
\hline Genetic disorders & $14(2.9)$ \\
\hline Association of extracardiac anomaly & $50(10.4)$ \\
\hline \multicolumn{2}{|l|}{ Primary diagnosis } \\
\hline HLHS & $120(24.8)$ \\
\hline DILV & $70(14.5)$ \\
\hline $\mathrm{TA}$ & $73(15.1)$ \\
\hline PAIVS & $24(5.0)$ \\
\hline ccTGA & $24(5.0)$ \\
\hline Unbalanced AVSD & $12(2.5)$ \\
\hline \multicolumn{2}{|l|}{ AVV morphology } \\
\hline Single TV & $167(34.6)$ \\
\hline Two AVV & $160(33.1)$ \\
\hline Single MV & $110(22.8)$ \\
\hline Common AVV & $46(9.5)$ \\
\hline \multicolumn{2}{|l|}{ Associated cardiac anomaly } \\
\hline TGA & $189(39.1)$ \\
\hline DORV & $70(14.5)$ \\
\hline $\mathrm{CoA}$ & $65(13.5)$ \\
\hline Dextrocardia & $43(8.9)$ \\
\hline Heterotaxy & $38(7.9)$ \\
\hline Dominant right ventricle & $261(54.0)$ \\
\hline Pulmonary venous return anomaly & $35(7.2)$ \\
\hline Anomalous systemic venous drainage & $53(11.0)$ \\
\hline Bilateral SVC & $48(9.9)$ \\
\hline Hepatic vein anomaly & $7(1.4)$ \\
\hline Azygos continuation & $16(3.3)$ \\
\hline \multicolumn{2}{|l|}{ Palliation and pre-Fontan condition } \\
\hline Norwood/DKS procedure & $199(41.2)$ \\
\hline PAB & $78(16.1)$ \\
\hline Pulmonary artery reconstruction & $148(30.6)$ \\
\hline AVV operation & $50(10.4)$ \\
\hline APCs & $126(26.1)$ \\
\hline Previous BCPS & $434(89.9)$ \\
\hline Age at BCPS & $0.5(0.3-1.0)$ \\
\hline Interval BCPS and TCPC & $1.6(1.2-2.2)$ \\
\hline
\end{tabular}

$I Q R$, Interquartile ranges; $T C P C$, total cavopulmonary connection; $H L H S$, hypoplastic left heart syndrome; $D I L V$, double inlet left ventricle; $T A$, tricuspid atresia; PAIVS, pulmonary atresia and intact ventricular septum; $c c T G A$, congenitally corrected transposition of the great arteries; $A V S D$, atrioventricular septal defect; $A V V$, atrioventricular valve; $T V$, tricuspid valve; $M V$, mitral valve; $T G A$, transposition of the great arteries; $D O R V$, double outlet right ventricle; $C O A$, coarctation of the aorta; $S V C$, superior vena cava; $D K S$, Damus-Kaye-Stansel; $P A B$, pulmonary artery banding; $A P C s$, aortopulmonary collaterals; $B C P S$, bidirectional cavopulmonary shunt.

\section{Operative and Perioperative Data}

The operative data are shown in Table 2. Lateral tunnelTCPC was performed in $50(10.4 \%)$ patients and extracardiac conduit-TCPC was performed in $433(89.6 \%)$ patients. The median cardiopulmonary bypass (CPB) time was $64 \mathrm{mi}-$ nutes, and $139(28.8 \%)$ patients needed aortic crossclamp.
Concomitant AVV procedure was performed in $69(14.3 \%)$ patients. The median ICU LOS was 7 (interquartile range 5-9) days. Pleural effusion needing drainage more than $>7$ days and/or needing redrainage during the ICU stay was observed in $236(49 \%)$ patients, chylothorax in 92 $(19 \%)$, ascites requiring drainage in $94(20 \%)$, tachyarrhythmia in $24(5 \%)$, infection in $10(2 \%)$, hepatic insufficiency in $8(2 \%)$, thromboembolic complication in $6(1 \%)$, and renal insufficiency in $5(1 \%)$. There were 20 patients, who demonstrated respiratory insufficiency and/or low arterial saturation postoperatively, and needed catheter intervention during the ICU stay. Catheter interventions included 9 stent implantations in the pulmonary artery (PA), 7 coil occlusions of APCs, 3 occlusions of venovenous collaterals, 3 balloon angioplasties of PA, and 1 stent implantation for re-coarctation of the aorta. A secondary fenestration was necessary in $7(1.4 \%)$ patients.

Eight patients died in ICU within 30 days, postoperatively. The causes of death are shown in Table E3. These patients were excluded from the risk analysis; because they discharged ICU without recovery and their ICU LOS were inappropriate for analysis of probability of ICU discharge.

\section{Factors Associated With Length of ICU Stay}

The preoperative factors influencing ICU stay were analyzed with Cox regression model. The results are shown in Table E1. The following potentially important factors had no significant $P$ values: age at TCPC $(P=.202)$, weight at TCPC $(P=.159)$, nonstaged Fontan completion $(P=.457)$, and age at BCPS $(P=.174)$, and impaired ventricular function $(P=.647)$.

Figure 1 demonstrates the $P$ value, hazard ratio (HR), and 95\% confidence interval (CI) of significant preoperative variables with univariate Cox regression analysis. Among morphologic variables, HLHS $(P=.039)$, single tricuspid valve $(P=.010)$, dextrocardia $(P=.062)$, anomalous $\operatorname{SVD}(P=.003)$, and dominant $\mathrm{RV}(P=.001)$ were identified as risk factors for the longer ICU LOS with univariate analysis (Figure 1). Among hemodynamic variables, preoperative high hemoglobin levels $(P=.058)$, high mean PAP $(P=.054)$, high TPG $(P=.040)$, low $\mathrm{SO}_{2}(P=.039)$, and presence of APCs $(P=.081)$ were identified as risk in the univariate model. As for preoperative ventricular and AVV function, preoperative impaired ventricular function did not influence the ICU LOS $(P=.708)$. However, presence of significant AVV regurgitation $(P=.064)$ was a risk for the ICU LOS with univariate analysis. In the multivariate model, anomalous SVD $(P<.01)$, HLHS $(P=.001)$, high TPG $(P=.037)$, and low $\mathrm{SO}_{2}(P=.031)$ were identified as independent risks for the longer ICU LOS. KaplanMeier curves comparing the time to ICU discharge after a TCPC procedure for the patients with and without anomalous SVD was shown in Figure 2. 
TABLE 2. Perioperative variables and their association with ICU LOS

\begin{tabular}{|c|c|c|}
\hline Variables & N (\%) or median (IQR) & $P$ value \\
\hline Number of patients & 483 & \\
\hline \multicolumn{3}{|l|}{ Operative data } \\
\hline Type of TCPC & & .869 \\
\hline Intracardial & $50(10.4)$ & \\
\hline Extracardiac & $433(89.6)$ & \\
\hline Early era (before 2009) & $251(52.0)$ & .002 \\
\hline $\mathrm{CPB}$ time, $\min$ & $64(45-103)$ & .003 \\
\hline AXC & $139(28.8)$ & .089 \\
\hline AXC time, $\min$ & $46(26-73)$ & .400 \\
\hline Concomitant procedure & $153(31.7)$ & .100 \\
\hline DKS & $12(2.5)$ & .177 \\
\hline AVV procedure & $69(14.3)$ & .030 \\
\hline PA reconstruction & $54(11.2)$ & .992 \\
\hline Atrioseptectomy & $23(4.8)$ & .292 \\
\hline SAS/VSD enlargement & $8(1.7)$ & .569 \\
\hline Pacemaker implantation & $9(1.9)$ & .117 \\
\hline Fenestration at TCPC & $35(7.2)$ & .317 \\
\hline \multicolumn{3}{|l|}{ Postoperative data } \\
\hline Ventilation time, $\mathrm{h}$ & $9(4-20)$ & \\
\hline Chest tube drainage, $\mathrm{d}$ & $4(2-6)$ & \\
\hline Reintubation & $30(6.2)$ & \\
\hline ICU stay, $\mathrm{d}$ & $7(5-9)$ & \\
\hline Hospital stay, d & $20(14-28)$ & \\
\hline \multicolumn{3}{|l|}{ Complications } \\
\hline Pleural effusion & $198(41.0)$ & \\
\hline Chylothorax & $91(18.8)$ & \\
\hline Ascites & $95(19.7)$ & \\
\hline Arrhythmia & $21(4.3)$ & \\
\hline Infection & $9(1.9)$ & \\
\hline Hepatic insufficiency & $8(1.7)$ & \\
\hline Thromboembolism & $5(1.0)$ & \\
\hline Renal insufficiency & $5(1.0)$ & \\
\hline Secondary fenestration & $7(1.4)$ & \\
\hline
\end{tabular}

Bold indicates $P<.05 . I Q R$, Interquartile ranges; $I C U$, intensive care unit; $L O S$, length of stay; $T C P C$, total cavopulmonary connection; $C P B$, cardiopulmonary bypass; $A X C$, aortic crossclamp; DKS, Damus-Kaye-Stansel anastomosis; $A V V$, atrioventricular valve; $P A$, pulmonary artery; $S A S$, subaortic stenosis; $V S D$, ventricular septal defect.

Among 128 patients presented with significant APCs, 60 $(46.9 \%)$ patients underwent intervention preoperatively and/or intraoperatively (36 coil embolization, 25 intraoperative closures at the TCPC, and 3 intraoperative closures at the BCPS). There was no significant difference in the ICU LOS between the patients with and without APCs closure pre/at TCPC $(P=.503)$. Postoperatively, 22 patients $(17.2 \%)$ needed coil embolization of APCs. When these 22 patients were compared with the remaining 108 patients, postoperative ICU LOS was significantly longer in these patients $(P=.011)$.

Era analysis was performed. Early era was a significant risk for longer ICU $\operatorname{LOS}(P=.002 ; \mathrm{HR}, 1.027 ; 95 \% \mathrm{CI}$, $1.010-1.044)$. When era was included in multivariable models, era $(P<.001$; HR, 1.045; 95\% CI, 1.024-1.067),
HLHS ( $P<.001$; HR, 1.610; 95\% CI, 1.262-2.053), anomalous SVD $(P=.001$; HR, 1.748, 95\% CI, 1.267-2.409), low $\mathrm{SO}_{2}(P=.010 ; \mathrm{HR}, 1.025,95 \% \mathrm{CI}, 1.006-1.044)$, and APCs $(P=.008$; HR, 1.367, 95\% CI, 1.083-1.724) were identified as independent risk factors.

Among operative variables, type of TCPC $(P=.869)$ and fenestration at TCPC $(P=.317)$ had no significant $P$ values (Table 2). CPB time $(P=.003$; HR, $1.003 ; 95 \%$ CI, 1.001 $1.005)$ and concomitant AVV procedure $(P=.030$; HR, $1.342,95 \%$ CI, 1.029-1.751) were the variables, which had significant $P$ value $<.05$.

Postoperative variables associated with the ICU LOS were analyzed using Cox model with time varying covariates. As results, pleural effusion $(P<.001)$, chylothorax $(P=.001)$, ascites $(P<.001)$, and infection $(P=.029)$ were significantly associated with the ICU LOS (Table 3).

\section{Impact of the ICU LOS on Late Outcomes}

Of the 475 early survivors, 10 patients $(2.1 \%)$ were lost to follow-up after hospital discharge. The median length of follow-up was 6 (1.5-11.6) years for the remaining 465 patients. Fifteen patients experienced a late death. The causes of death are shown in Table E3. One patient required heart transplantation 5 months after TCPC. The estimated overall survival is demonstrated in Figure E1. A cardiac reoperation was necessary for 40 patients $(27.3 \%)$ in group A (13 AVV procedures, 4 aortic valve procedures, 5 ascending aorta/ aortic arch procedures, 7 revision of the TCPC tunnel, and 1 resection of a subaortic stenosis, 1 PA procedure, and 10 secondary fenestration procedures; 1 patient had 2 procedures concomitantly). The estimated freedom from cardiac reoperation is demonstrated in Figure E2. A catheter intervention was required for 88 patients: freedom from a catheter intervention is demonstrated in Figure E3. According to the Cox regression model, risk factor analysis for late mortality, late cardiac reoperation, and late catheter intervention was performed (Table 4). As a result, the ICU LOS was a significant risk factor for late mortality $(P<.001)$, late cardiac reoperation $(P<.001)$, and late catheter intervention $(P=.014)$ in the univariate model. Furthermore, the ICU LOS was found to be significantly associated with mortality and late reoperation in the multivariate model.

\section{DISCUSSION}

In this study, HLHS, anomalous SVD, preoperative high TPG, and preoperative low $\mathrm{SO}_{2}$ were independent risk factors for the ICU LOS. The main causes of the longer ICU LOS were pleural effusion, chylothorax, and ascites. The ICU LOS was found to be significantly associated with late mortality and late reoperation (Video 1 ).

\section{Risk Factors for Prolonged ICU Stay}

Our results demonstrated that dominant RV, single TV, and HLHS were the risk factors for the longer ICU LOS. 


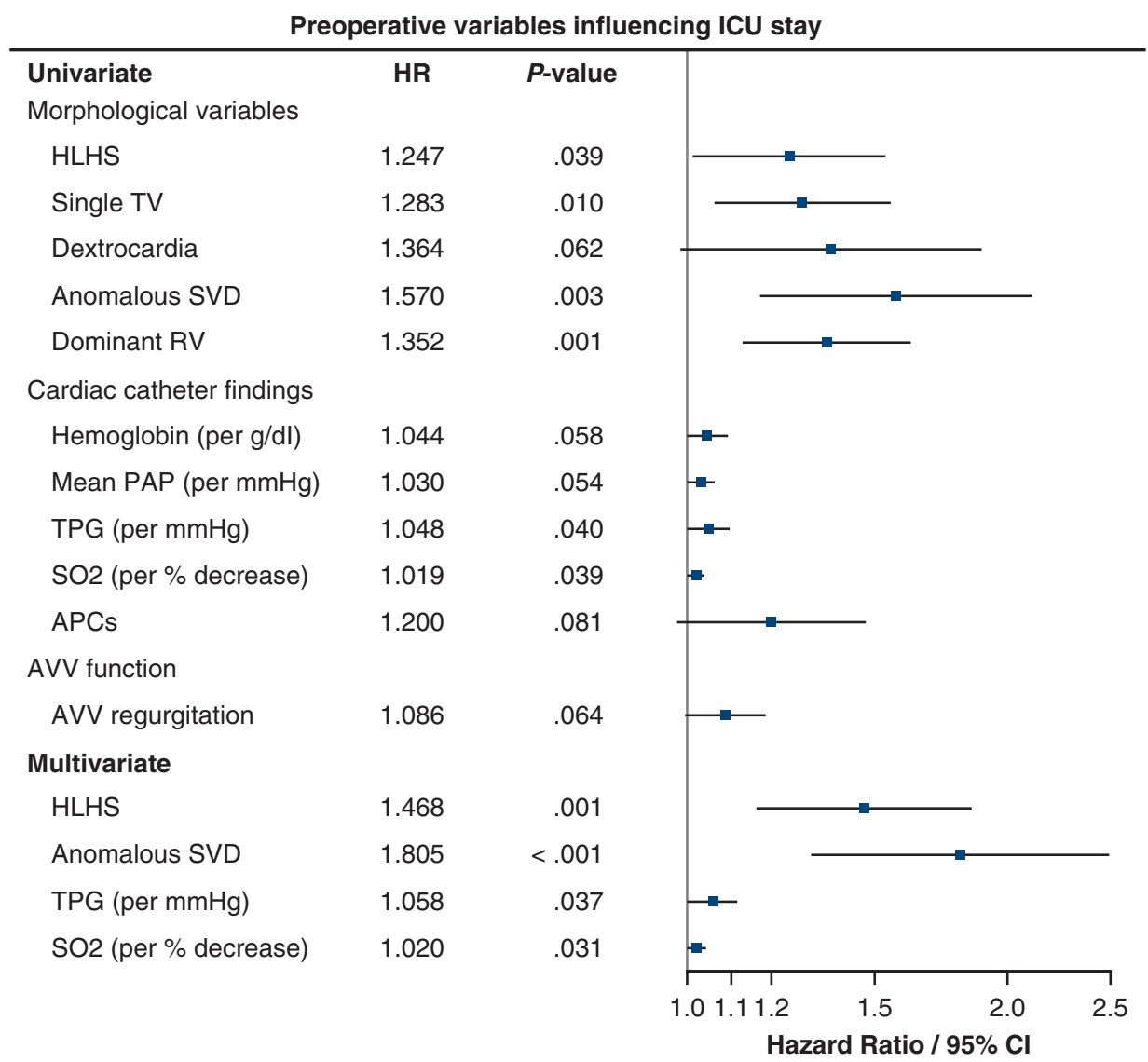

FIGURE 1. Preoperative risk factors that influenced ICU LOS after total cavopulmonary connection analyzed with a Cox regression model. Graphic demonstrates the HR (blue square) and 95\% CI (black linear). Among morphologic variables, HLHS, single TV, dextrocardia, anomalous SVD, and dominant RV were significant risk factors with univariate analysis. Among cardiac catheter findings, greater hemoglobin level, greater mean PAP, greater TPG, lower $\mathrm{SO}_{2}$, presence of APCs, and AVV regurgitation were significant risk factors with univariate analysis. With multivariate analysis, HLHS, anomalous SVD, greater TPG, and lower $\mathrm{SO}_{2}$ were identified as independent risk factors for longer ICU LOS. ICU, Intensive care unit; $H R$, hazard ratio; $H L H S$, hypoplastic left heart syndrome; $T V$, tricuspid valve; $S V D$, systemic venous drainage; $R V$, right ventricle; $P A P$, pulmonary artery pressure; $T P G$, transplumonary gradient; $\mathrm{SO}_{2}$, arterial oxygen saturation; $A P C s$, aortopulmonary collaterals; $A V V$, atrioventricular valve; $C I$, confidence interval.

Although a recent study ${ }^{15}$ and our previous study ${ }^{2}$ demonstrated that dominant RV is not a risk for mortality after Fontan procedure, dominant RV has been reported as a risk for staged reconstruction of single ventricle. Nordmeyer and colleagues ${ }^{3}$ demonstrated that patients with systemic RV needed a longer ICU LOS compared with those with a systemic left ventricle in their 173 consecutive patients who underwent TCPC. d'Udekem and colleagues ${ }^{16}$ demonstrated RV dominance was a risk for mortality before BCPS. Alsoufi and colleagues ${ }^{17}$ suggested dominant RV and associated tricuspid valve failure might influence the late outcomes. Furthermore, Iyengar and colleagues ${ }^{4}$ reported that dominant RV and HLHS were associated with prolonged effusions, and HLHS was the strongest risk factor with multivariate model. These results were quite consistent with our results.

In this study, anomalous SVD also was identified as an independent risk for longer ICU LOS. Anomalous SVD included bilateral superior vena cava, azygos continuation, and anomalous hepatic venous drainage. Bilateral superior vena cava was the most common form of this anomaly and needed bilateral BCPS. It produces flow stagnation at the level of the PA confluence leading to unfavorable growth of the central PAs. The special flow dynamics after bilateral BCPS might influence the longer ICU LOS after Fontan completion. Another explanation might be that anomalous SVD surrogates for the complex type of single ventricle other than HLHS. Typical configuration is RVtype single ventricle, transposition of the great arteries or double outlet right ventricle, common AVV or single tricuspid valve, frequently associated with anomalous pulmonary venous drainage, dextrocardia, and/or heterotaxy. Our results demonstrated frequent association with anomalous SVD and these morphologic features. The complexity of the anatomy might require additional surgical procedures and present with worse pre-Fontan 


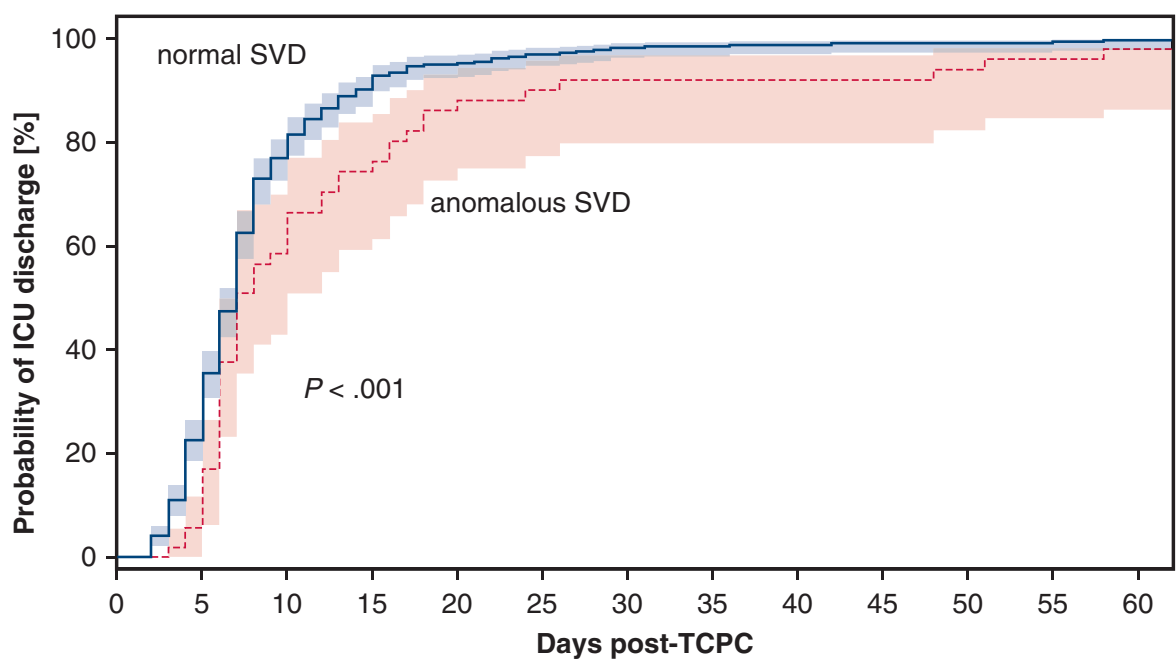

patients in ICU

$\begin{array}{ccccccccccc}430 & 331 & 96 & 41 & 20 & 12 & 7 & 6 & 4 & 3 & \text { - normal SVD } \\ 53 & 50 & 21 & 13 & 7 & 5 & 4 & 4 & 4 & 4 & -- \text { anomalous SVD }\end{array}$

FIGURE 2. Kaplan-Meier curves comparing the time to ICU discharge after a TCPC procedure for the patients with and without anomalous SVD. The patients associated with anomalous SVD needed significantly longer time to ICU discharge $(P<.001$ by log-rank test). ICU, Intensive care unit; TCPC, total cavopulmonary connection; $S V D$, systemic venous drainage.

conditions. These associated conditions might result in longer ICU LOS.

Our results demonstrated that certain hemodynamic and laboratory factors, such as preoperative greater PAP, greater TPG, greater hemoglobin levels, and lower $\mathrm{SO}_{2}$, were also associated with longer ICU LOS. These factors might be representative of patients' condition with extended cyanosis, underdevelopment/hypoplasia of PAs, and high pulmonary vascular resistance. These clinical findings were quite similar to the reports from Gupta and colleagues ${ }^{6}$ and Sasaki and colleagues. ${ }^{18}$ The presence of APCs was also identified as a risk for longer ICU LOS. In a study using cardiac magnetic resonance, Grosse-Wortmann and colleagues ${ }^{19}$ assessed APC blood flow quantitatively and demonstrated that patients with a BCPS routinely acquire a large amount of APC flow and that the hemodynamic

TABLE 3. Postoperative variables influencing ICU stay using Cox model with time varying covariates

\begin{tabular}{lcc}
\hline \multicolumn{1}{c}{ Variables } & $\boldsymbol{P}$ value & HR $(\mathbf{9 5} \% \mathbf{C I})$ \\
\hline Pleural effusion & $<.001$ & $2.467(1.66-4.781)$ \\
Chylothorax & .001 & $1.463(1.10-2.20)$ \\
Ascites & $<.001$ & $2.333(1.51-5.15)$ \\
Arrhythmia & .779 & $1.061(0.74-1.85)$ \\
Infection & .029 & $2.039(0.90-7.38)$ \\
Hepatic insufficiency & .218 & $1.515(0.76-85.64)$ \\
Thromboembolism & .280 & $0.614(0.40-1.31)$ \\
Renal insufficiency & .223 & $1.662(0.71-4.99)$ \\
\hline
\end{tabular}

$H R$, Hazard ratio; $C I$, confidence interval. consequences of APC flow translate into adverse outcomes early after TCPC. Odenwald and colleagues ${ }^{20}$ also demonstrated patients with greater APC flow had increased postoperative chest drain volume, chest drain duration, and ICU stay after TCPC. In our study, APCs were observed approximately one third of patients, and the presence of APCs influenced the ICU LOS. The precise mechanism through which APCs adversely affect the early postoperative outcomes in these patients is still incompletely understood. Maybe there is a confounding variable such as elevated pulmonary vascular resistance and extended cyanosis that independently causes the APC development and an adverse postoperative outcome. This is an area that warrants further study.

Generally, the Fontan circuit relies on systemic venous pressure to propel blood through the lungs; it therefore depends on low pulmonary vascular resistance, which in turn is affected by such factors as PA distortion or increased time intervals in infancy with high pressure or volume load of the pulmonary circulation. Longer ICU LOS, an indication of postoperative morbidities, appears a potential consequent of underlying complexity and sub-optimal conditions for Fontan completion. ICU LOS may be a surrogate for other patient or operation related risk factors.

\section{Causes of Longer ICU LOS and Therapeutic Options}

Although it is not possible to identify the exact reasons why individual patients remained in the ICU, pleural effusion, chylothorax, and ascites were the main complications most strongly associated with long ICU LOS. The factor 
TABLE 4. Risk factor analysis for late outcomes based on the Cox regression model

\begin{tabular}{|c|c|c|c|c|}
\hline \multirow[b]{2}{*}{ Variables } & \multicolumn{2}{|c|}{ Univariable model } & \multicolumn{2}{|c|}{ Multivariable model } \\
\hline & $P$ value & HR $(95 \%$ CI $)$ & $\overline{P \text { value }}$ & HR $(95 \%$ CI $)$ \\
\hline \multicolumn{5}{|l|}{ Late mortality $(>30 \mathrm{~d})$} \\
\hline Length of ICU stay & $<.001$ & $1.045(1.030-1.061)$ & $<.001$ & $1.041(1.024-1.058)$ \\
\hline HLHS & .188 & & & \\
\hline Single TV & .594 & & & \\
\hline Dextrocardia & .016 & & & \\
\hline Anomalous SVD & .015 & $3.692(1.283-10.630)$ & & \\
\hline Dominant RV & .967 & & & \\
\hline Hemoglobin levels & .051 & & & \\
\hline Mean PAP & .009 & $1.172(1.041-1.319)$ & .044 & $1.130(1.004-1.272)$ \\
\hline TPG & .009 & $1.256(1.057-1.493)$ & & \\
\hline $\mathrm{SO} 2$ & .385 & & & \\
\hline APCs & .796 & & & \\
\hline Heterotaxy & .019 & $3.885(1.252-12.055)$ & & \\
\hline \multicolumn{5}{|l|}{ Late cardiac reoperation } \\
\hline Length of ICU stay & $<.001$ & $1.029(1.013-1.046)$ & .007 & $1.024(1.006-1.042)$ \\
\hline HLHS & .057 & $1.971(0.979-3.967)$ & & \\
\hline Single TV & .021 & $2.129(1.121-4.045)$ & & \\
\hline Dextrocardia & .257 & & & \\
\hline Anomalous SVD & .271 & & & \\
\hline Dominant RV & .012 & $2.424(1.216-4.829)$ & .011 & $2.532(1.232-5.025)$ \\
\hline Hemoglobin levels & .668 & & & \\
\hline Mean PAP & .258 & & & \\
\hline TPG & .023 & $1.160(1.021-1.319)$ & .049 & $1.135(1.001-1.286)$ \\
\hline $\mathrm{SO}_{2}$ & .137 & & & \\
\hline APCs & .845 & & & \\
\hline Anomalous PVD & .032 & $2.815(1.091-7.261)$ & & \\
\hline AVV operation & .005 & $2.538(1.324-4.867)$ & & \\
\hline \multicolumn{5}{|l|}{ Late intervention } \\
\hline Length of ICU stay & .014 & $1.018(1.004-1.033)$ & & \\
\hline HLHS & .001 & $2.070(1.324-3.238)$ & & \\
\hline Single TV & .002 & $1.932(1.264-2.951)$ & & \\
\hline Dextrocardia & .588 & & & \\
\hline Anomalous SVD & .915 & & & \\
\hline Dominant RV & $<.001$ & $2.430(1.538-3.837)$ & .001 & $2.388(1.436-3.971)$ \\
\hline Hemoglobin levels & .249 & & & \\
\hline Mean PAP & .018 & $1.073(1.012-1.137)$ & .008 & $1.094(1.023-1.169)$ \\
\hline TPG & .216 & & & \\
\hline $\mathrm{SO}_{2}$ & .039 & $0.958(0.919-0.998)$ & .029 & $0.958(0.922-0.996)$ \\
\hline APCs & $<.001$ & $2.488(1.619-3.823)$ & $<.001$ & $2.393(1.476-3.880)$ \\
\hline $\mathrm{CoA}$ & .026 & $1.783(1.073-2.963)$ & .010 & $2.672(1.189-3.612)$ \\
\hline
\end{tabular}

$H R$, Hazard ratio; $C I$, confidence interval; $I C U$, intensive care unit; $H L H S$, hypoplastic left heart syndrome; $T V$, tricuspid valve; $S V D$, systemic venous drainage; $R V$, right ventricle; $P A P$, pulmonary artery pressure; $T P G$, transpulmonary gradient; $S_{2}$, aortic oxygen saturation; $A P C s$, aortopulmonary collaterals; $P V D$, pulmonary venous drainage; $A V V$, atrioventricular valve; $C O A$, coarctation of the aorta.

most strongly associated with long ICU LOS was prolonged postoperative pleural effusion. This traditionally reported morbidity has been considered a marker of suboptimal hemodynamics, although the underlying mechanism is poorly understood. This may relate at least in part to noncardiac comorbidities, not explicitly captured as covariates in the study. Pleural effusions after the Fontan procedure are unpredictable. Development of pulmonary vasculature, pulmonary vascular resistance, and obstruction of PAs might influence the postoperative effusions. Our results of hemodynamic and laboratory data suggest this hypothesis. The influence of APCs is also thought to be one of the possible mechanisms. In our study, APCs were frequently observed in approximately one third of patients, and the presence of APCs had influence on the ICU LOS.

Although our results demonstrated that preoperative ventricular dysfunction did not affect the ICU LOS, postoperative ventricular dysfunction might cause the pleural 


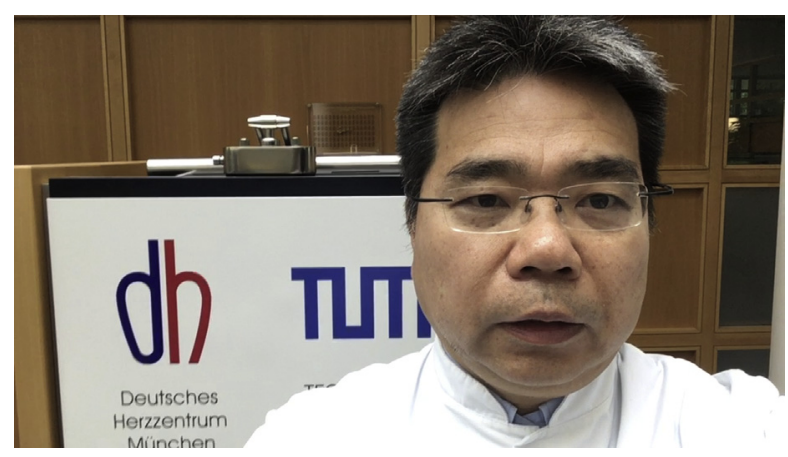

VIDEO 1. Video of the author explaining the importance and relevance of this study. Video available at: https://www.jtcvs.org/article/S0022-5223(18) 32964-7/fulltext.

effusion. Garofalo and colleagues ${ }^{21}$ demonstrated that ventricular diastolic stiffness predicts perioperative morbidity and duration of pleural effusions after the Fontan operation. It was typically observed in nonstaged older patients or in patients with significant AVV regurgitation requiring concomitant AVV repair at TCPC.

Therapy includes diuretics and surgical drainage of effusions, surgical, and catheter intervention for pathway obstruction, and secondary fenestration for early Fontan failure. A defined management strategy might reduce the amount of effusion and shorten the ICU LOS. ${ }^{22,23}$ Since 2009, our institution adopted an early extubation strategy, ${ }^{14}$ and impact of this strategy on late outcomes should be analyzed in the future study.

Surgical approaches to shortening ICU LOS include optimal development of PAs and assessment of APCs before Fontan completion. Preoperative PA condition is thought to be the variable that has the biggest impact on the ICU LOS. Our results demonstrated that greater PAP and greater TPG were predictors of longer ICU LOS. As for the assessment of APCs, routine cardiac magnetic resonance to measure the volume of APC blood flow might further our understanding of pulmonary vascular condition and lead to management strategies to prevent persistent effusion after Fontan procedure.

\section{Indication for Fenestration}

It is still controversial whether fenestration should be created at the time of Fontan completion. In their prospective, randomized study, Lemler and colleagues ${ }^{9}$ demonstrated that fenestration at time of Fontan surgery improved short-term outcome by decreasing pleural drainage, hospital LOS, and need for additional postoperative procedures. In our study, fenestration was created in a small number of patients. Therefore, it is impossible to evaluate the effect of fenestration on postoperative outcomes. Our results demonstrated that most of the patients could accomplish Fontan completion without fenestration. Presently, we can manage post-Fontan patients well without fenestration, using short CPB time, modified ultrafiltration, early extubation, and physiotherapy. However, the relative long ICU LOS in our study might be partially due to our nonfenestration policy. We believe that fenestration is not necessary for optimal Fontan candidates. However, we cannot always obtain optimal condition for all Fontan candidates. In this context, fenestration should be reconsidered for patients with risks identified in this study.

\section{Study Limitations}

This study was limited by its retrospective and singlecenter design. Data were not available at consistent follow-up periods for every patient. Changes over time in surgical and medical management might have affected the outcomes. Reasons for longer ICU LOS might vary between hospitals. In our center, patients requiring drains for pleural effusion are generally treated on the ICU until drains are removed. This can make results not comparable with other reports.

\section{CONCLUSIONS}

In conclusion, certain morphologic and hemodynamic features were associated with patients who had longer ICU LOS after TCPC. Similar to previous report, longer ICU LOS is a significant risk factor for late outcomes. ICU LOS may be a surrogate for other patient or operation-related risk factors. Special attention is needed for postoperative care in patients with HLHS and anomalous SVD. Presence of untreated APCs might cause the postoperative complications.

\section{Conflict of Interest Statement}

Authors have nothing to disclose with regard to commercial support.

We thank Dr Alexander Hapfelmeier, Institute of Medical Information, Statistic and Epidemiology, Technical University of $\mathrm{Mu}-$ nich, for his assistance with statistical analysis.

\section{References}

1. Downing TE, Allen KY, Glatz AC, Rogers LS, Ravishankar C, Rychik J, et al. Long-term survival after the Fontan operation: twenty years of experience at a single center. J Thorac Cardiovasc Surg. 2017;154:243-53.

2. Ono M, Kasnar-Samprec J, Hager A, Cleuziou J, Burri M, Langenbach C, et al. Clinical outcome following total cavopulmonary connection — a 20-year single center experience. Eur J Cardiothorac Surg. 2016;50:632-41.

3. Nordmeyer S, Rohder M, Nordmeyer J, Miera O, Peters B, Cho MY, et al. Systemic right ventricular morphology in the early postoperative course after extracardiac Fontan operation: is there still a need for special care? Eur J Cardiothorac Surg. 2017;51:483-9.

4. Iyengar AJ, Winlaw DS, Galati JC, Celermajer DS, Wheaton GR, Gentles TL, et al. Trends in Fontan surgery and risk factors for early adverse outcomes after Fontan surgery: the Australia and New Zealand Fontan Registry experience. J Thorac Cardiovasc Surg. 2014;148:566-75.

5. Ravishankar C, Gerstenberger E, Sleeper LA, Atz AM, Affolter JT, Bradley TJ, et al; Pediatric Heart Network Investigators. Factors affecting Fontan length of stay: results from the Single Ventricle Reconstruction trial. J Thorac Cardiovasc Surg. 2016;151:669-75. 
6. Gupta A, Daggett C, Behera S, Ferraro M, Wells W, Starnes V. Risk factors for persistent pleural effusions after the extracardiac Fontan procedure. J Thorac Cardiovasc Surg. 2004;127:1664-9.

7. Salvin JW, Scheurer MA, Laussen PC, Mayer JE Jr, Del Nido PJ, Pigula FA, et al. Factors associated with prolonged recovery after the Fontan operation. Circulation. 2008;118(14 suppl):S171-6.

8. Salam S, Dominguez T, Tsang V, Giardini A. Longer hospital stay after Fontan completion in the November to March period. Eur J Cardiothorac Surg. 2015;47:262-8.

9. Lemler MS, Scott WA, Leonard SR, Stromberg D, Ramaciotti C. Fenestration improves clinical outcome of the Fontan procedure: a prospective, randomized study. Circulation. 2002;105:207-12.

10. Schreiber C, Hörer J, Vogt M, Cleuziou J, Prodan Z, Lange R. Nonfenestrated extracardiac total cavopulmonary connection in 132 consecutive patients. Ann Thorac Surg. 2007;84:894-9.

11. Ono M, Beran E, Burri M, Cleuziou J, Pabst von Ohain J, Strbad M, et al. Longterm outcome of preadolescents, adolescents, and adult patients undergoing total cavopulmonary connection. J Thorac Cardiovasc Surg. 2018;156:1166-76.e4.

12. Ono M, Cleuziou J, Pabst von Ohain J, Beran E, Burri M, Strbad M, et al. Atrioventricular valve regurgitation in patients undergoing total cavopulmonary connection: impact of valve morphology and underlying mechanisms on survival and reintervention. J Thorac Cardiovasc Surg. 2018;155:701-9.

13. Schreiber C, Cleuziou J, Cornelsen JK, Hörer J, Eicken A, Lange R. Bidirectional cavopulmonary connection without additional pulmonary blood flow as an ideal staging for functional univentricular hearts. Eur J Cardiothorac Surg. 2008;34:550-4.

14. Georgiev S, Balling G, Ruf B, Ackermann K, Pabst von Ohain JP, Schreiber C, et al. Early postoperative extubation of unstable patients following total cavopulmonary connection: impact on circulation and outcome. Cardiol Young. 2017;27:860-9.

15. Atz AM, Zak V, Mahony L, Uzark K, D'agincourt N, Goldberg DJ, et al. Longitudinal outcomes of patients with single ventricle after the Fontan procedure. $J$ Am Coll Cardiol. 2017;69:2735-44.
16. d'Udekem Y, Xu MY, Galati JC, Lu S, Iyengar AJ, Konstantinov IE, et al. Predictors of survival after single-ventricle palliation: the impact of right ventricular dominance. J Am Coll Cardiol. 2012;59:1178-85.

17. Alsoufi B, Gillespie S, Kim D, Shashidharan S, Kanter K, Maher K, et al. The impact of dominant ventricle morphology on palliation outcomes of single ventricle anomalies. Ann Thorac Surg. 2016;102:593-601.

18. Sasaki J, Dykes JC, Sosa LJ, Salvaggio JL, Tablante MD, Ojito J, et al. Risk factors for longer hospital stay following the Fontan operation. Pediatr Crit Care Med. 2016;17:411-9.

19. Grosse-Wortmann L, Drolet C, Dragulescu A, Kotani Y, Chaturvedi R, Lee KJ, et al. Aortopulmonary collateral flow volume affects early postoperative outcome after Fontan completion: a multimodality study. J Thorac Cardiovasc Surg. 2012; 144:1329-36.

20. Odenwald T, Quail MA, Giardini A, Khambadkone S, Hughes M, Tann O, et al Systemic to pulmonary collateral blood flow influences early outcomes following the total cavopulmonary connection. Heart. 2012;98:934-40.

21. Garofalo CA, Cabreriza SE, Quinn TA, Weinberg AD, Printz BF, Hsu DT, et al Ventricular diastolic stiffness predicts perioperative morbidity and duration of pleural effusions after the Fontan operation. Circulation. 2006;114(1 suppl): I56-61.

22. Sunstrom RE, Muralidaran A, Gerrah R, Reed RD, Good MK, Armsby LR, et al A defined management strategy improves early outcomes after the Fontan procedure: the PORTLAND protocol. Ann Thorac Surg. 2015;99:148-55.

23. Pike NA, Okuhara CA, Toyama J, Gross BP, Wells WJ, Starnes VA. Reduced pleural drainage, length of stay, and readmissions using a modified Fontan management protocol. J Thorac Cardiovasc Surg. 2015;150:481-7.

Key Words: intensive care unit, total cavopulmonary connection, pleural effusion, hypoplastic left heart syndrome, anomalous systemic venous drainage 


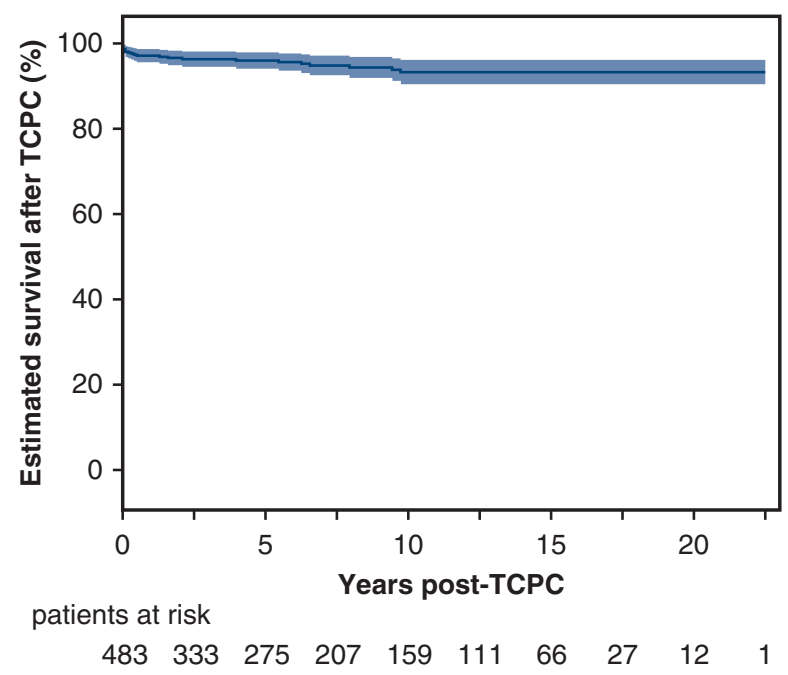

FIGURE E1. Estimated survival after TCPC. TCPC, Total cavopulmonary connection.

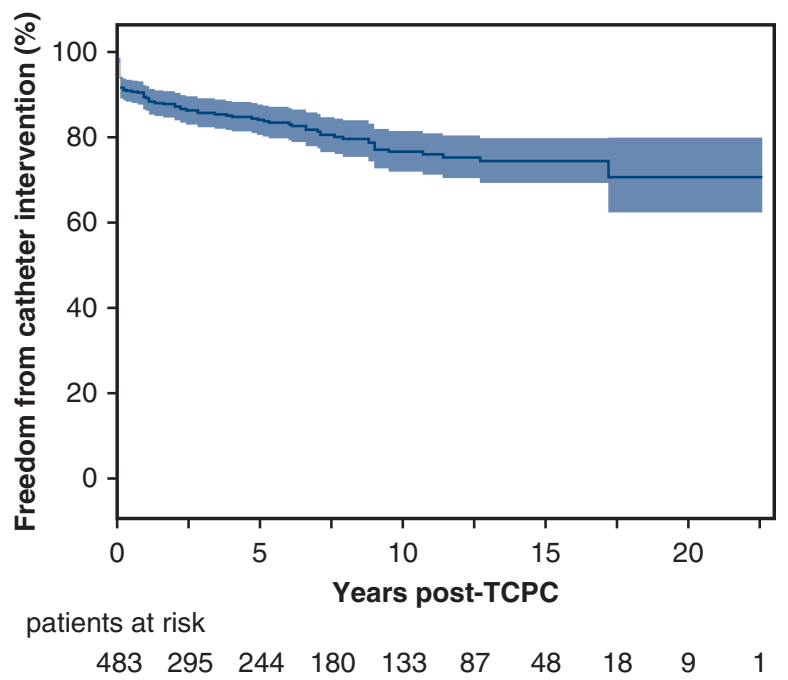

FIGURE E3. Freedom from intervention after TCPC. TCPC, Total cavopulmonary connection.

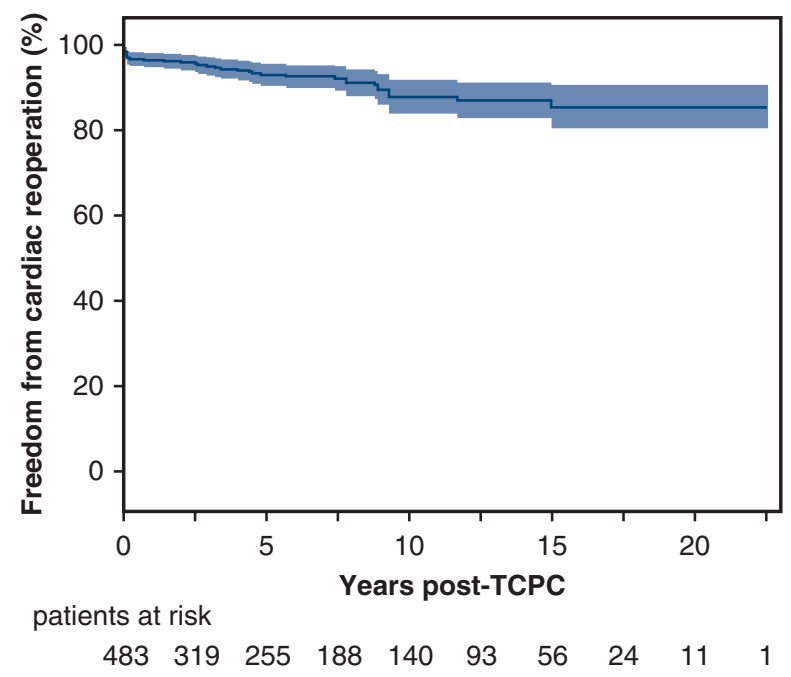

FIGURE E2. Freedom from reoperation after TCPC. TCPC, Total cavopulmonary connection. 
TABLE E1. Risk analysis for potentially preoperative variables influencing ICU stay

\begin{tabular}{|c|c|c|c|}
\hline Variables & $P$ value & HR & $95 \% \mathrm{CI}$ \\
\hline \multicolumn{4}{|l|}{ Baseline characteristics } \\
\hline Age at TCPC & .202 & & \\
\hline Weight at TCPC & .159 & & \\
\hline Associated genetic disorder & .107 & & \\
\hline Extracardiac anomaly & .187 & & \\
\hline \multicolumn{4}{|l|}{ Anatomic diagnosis } \\
\hline HLHS & .039 & 1.247 & 1.011-1.536 \\
\hline DILV & .424 & & \\
\hline TA & .051 & 0.779 & \\
\hline \multicolumn{4}{|l|}{ AVV morphology and function } \\
\hline Single TV & .010 & 1.283 & $1.060-1.553$ \\
\hline CAVV & .140 & & \\
\hline \multicolumn{4}{|l|}{ Associated anomaly } \\
\hline TGA & .033 & 0.817 & \\
\hline DORV & .938 & & \\
\hline $\mathrm{CoA}$ & .385 & & \\
\hline Dextrocardia & .062 & 1.364 & $0.985-1.890$ \\
\hline Heterotaxy syndrome & .152 & & \\
\hline Dominant RV & .001 & 1.352 & 1.127-1.623 \\
\hline Anomalous PVD & .105 & & \\
\hline Anomalous SVD & .003 & 1.570 & 1.170-2.110 \\
\hline \multicolumn{4}{|l|}{ Palliative and pre-TCPC procedures } \\
\hline Norwood/DKS procedure & .398 & & \\
\hline APS & .836 & & \\
\hline $\mathrm{PAB}$ & .195 & & \\
\hline Pacemaker implantation & .558 & & \\
\hline PA reconstruction & .979 & & \\
\hline AVV operation & .722 & & \\
\hline BCPS & .457 & & \\
\hline Age at BCPS & .174 & & \\
\hline \multicolumn{4}{|l|}{ Catheterization data at TCPC } \\
\hline Hemoglobin level, g/dL & .058 & 1.044 & 0.999-1.092 \\
\hline Mean pulmonary artery pressure, $\mathrm{mm} \mathrm{Hg}$ & .054 & 1.030 & $1.000-1.062$ \\
\hline Mean left atrium pressure, $\mathrm{mm} \mathrm{Hg}$ & 619 & & \\
\hline Transpulmonary gradient, $\mathrm{mm} \mathrm{Hg}$ & .040 & 1.048 & 1.002-1.096 \\
\hline Single-ventricle systolic pressure, $\mathrm{mm} \mathrm{Hg}$ & .165 & & \\
\hline Single-ventricle end-diastolic pressure, $\mathrm{mm} \mathrm{Hg}$ & .916 & & \\
\hline Aortic oxygen saturation ( $\%$, per $1 \%$ decrease) & .039 & 1.019 & 1.001-1.037 \\
\hline Presence of APCs & .081 & 1.200 & $0.978-1.473$ \\
\hline \multicolumn{4}{|l|}{ Ventricular and AVV function at TCPC } \\
\hline Impaired ventricular function $(\mathrm{EF}<50 \%)$ & .647 & & \\
\hline AVV regurgitation & .064 & 1.086 & 0.995-1.179 \\
\hline
\end{tabular}


TABLE E2. Pre-TCPC catheterization and echocardiographic data

\begin{tabular}{lc}
\hline \multicolumn{1}{c}{ Variables } & n (\%) or mean \pm SD \\
\hline Catheterization data & $\mathrm{n}=472$ \\
Hemoglobin, g/dL & $16.3 \pm 1.9$ \\
Mean pulmonary artery pressure, $\mathrm{mm} \mathrm{Hg}$ & $9.6 \pm 3.1$ \\
Mean left atrial pressure, mm Hg & $5.5 \pm 2.4$ \\
Transpulmonary gradient, mm Hg & $3.9 \pm 2.0$ \\
Systolic ventricular pressure, mm Hg & $82.9 \pm 13.5$ \\
Ventricular endo-diastolic pressure, mm Hg & $7.5 \pm 2.9$ \\
Aortic systolic pressure, mm Hg & $80.2 \pm 13.7$ \\
Aortic mean pressure, mm Hg & $57.2 \pm 10.8$ \\
Aortic oxygen saturation, \% & $82.6 \pm 5.4$ \\
APCs & $126(26.7)$ \\
Echocardiographic data & $\mathrm{n}=483$ \\
Ventricular dysfunction & \\
Normal & $439(90.9)$ \\
Impaired & $44(9.1)$ \\
Atrioventricular valve regurgitation & \\
None & $173(35.8)$ \\
Trivial & $160(33.1)$ \\
Mild & $87(18.0)$ \\
Moderate & $56(11.6)$ \\
Severe & $7(1.4)$ \\
\hline
\end{tabular}

SD, Standard deviation; $A P C s$, aortopulmonary collaterals.

TABLE E3. Characteristics of patients who died within 30 days or after 30 days after TCPC

\begin{tabular}{|c|c|c|c|c|c|}
\hline Case & Diagnosis & Age at TCPC, $y$ & Concomitant procedure & Cause of death & Period \\
\hline \multicolumn{6}{|c|}{ 30-d mortality } \\
\hline 1 & DILV & 2 & Dams-Kaye-Stansel & Cerebral infarction & $5 \mathrm{~d}$ \\
\hline 2 & imbalanced AVSD & 1 & AVV plasty & Cardiac failure & $2 \mathrm{~d}$ \\
\hline 3 & imbalanced AVSD & 4 & PLSVC closure & Cardiac failure & $9 \mathrm{~d}$ \\
\hline 4 & $\mathrm{SV}, \mathrm{CoA}$ & 12 & & Hepatic vein thrombosis & $17 \mathrm{~d}$ \\
\hline 5 & SV, TAPVC & 16 & & Cardiac failure & $8 \mathrm{~d}$ \\
\hline 6 & ccTGA, hypo TV & 1 & MV plasty, TV closure & Cardiac failure & $1 \mathrm{~d}$ \\
\hline 7 & DILV, TV straddling & 3 & TV plasty, atrioseptostomy & Cerebral infarction & $7 \mathrm{~d}$ \\
\hline 8 & IAA, small LV & 2 & & Cardiac failure & $5 \mathrm{~d}$ \\
\hline \multicolumn{6}{|c|}{ Late mortality } \\
\hline 1 & DILV, TGA & 5 & PA reconstruction & PLE & $10 \mathrm{y}$ \\
\hline 2 & SV, TGA & 2 & & Cardiac failure & $10 \mathrm{y}$ \\
\hline 3 & DIRV, DORV & 2 & & PLE & $4 y$ \\
\hline 4 & SV, TAPVC, heterotaxy & 5 & Dams-Kaye-Stansel & Cardiac failure, PLE & $1 \mathrm{y}$ \\
\hline 5 & SV, heterotaxy & 5 & & Sepsis & $2 \mathrm{mo}$ \\
\hline 6 & PAIVS & 11 & PA reconstruction, TV closure & Sudden death by delivery & $8 \mathrm{y}$ \\
\hline 7 & SV, CAVV, heterotaxy & 18 & AVV replacement & Cardiac failure & $4 \mathrm{mo}$ \\
\hline 8 & DILV & 3 & & Cardiac failure & $7 y$ \\
\hline 9 & SV, CAVV, heterotaxy & 10 & & hypoxia & $6 y$ \\
\hline 10 & HLHS & 1 & TV replacement & Cardiac failure & $1 \mathrm{y}$ \\
\hline 11 & DORV, hypo LV & 4 & MV closure & Cardiac failure & $3 \mathrm{mo}$ \\
\hline 12 & TA Ic & 3 & PV enlargement & Plastic bronchitis, MOF & $2 y$ \\
\hline 13 & TA Ic, CoA & 1 & & Encephalopathy & $6 y$ \\
\hline 14 & TA Ib & 1 & & Virus infection & $2 \mathrm{mo}$ \\
\hline 15 & SV, MA & 1 & & MOF & $1 \mathrm{mo}$ \\
\hline
\end{tabular}

$T C P C$, Total cavopulmonary connection; $D I L V$, double inlet left ventricle; $A V S D$, atrioventricular septal defect; $A V V$, atrioventricular valve; $P L S V C$, persistent left superior vena cava; $S V$, single ventricle; $C O A$, coarctation of the aorta; $T A P V C$, total anomalous pulmonary venous connection; $c c T G A$, congenitally corrected transposition of the great arteries; hypo, hypoplastic; $T V$, tricuspid valve; $M V$, mitral valve; $I A A$, interruption of the aorta; $L V$, left ventricle; $P A$, pulmonary artery; $P L E$, protein losing enteropathy; $T G A$, transposition of the great arteries; DIRV, double-inlet right ventricle; DORV, double-outlet right ventricle; PAIVS, pulmonary atresia intact ventricular septum; CAVV, common atrioventricular valve; $H L H S$, hypoplastic left heart syndrome; $T A$, tricuspid atresia; $M O F$, multiple organ failure; $M A$, mitral atresia. 